DOI: $10.37393 / J A S S .2020 .01 .7$

\title{
RESEARCH ON ANTHROPOMETRIC FACTORS AND BALANCE STABILITY OF FIGURE SKATERS
}

\author{
Tatiana Yordanova \\ National Sports Academy "Vassil Levski”, Sofia, Bulgaria
}

\section{ORCID}

Tatiana Yordanova https://orcid.org/0000-0002-7750-5774

\begin{abstract}
One of the characteristics of modern figure skating is the progressive complication of the competitive programs. This process develops, in particular, in the way of athletes' mastery of complex coordination elements and compounds of a rotating nature, which appear to be a strong irritant to the vestibular analyzer. The aim of the present study was to investigate the influence of anthropometric factors on the balance stability of female figure skaters. The study's tasks, which are divided into three groups, as well as the subject and object of the study, are presented. The used methods are described. The methodology of the study is separated and detailed. Also, the different abilities of the body for balance resistance, in various motor actions are described. One of the main used methods is called Stabilometry. The design of the study is followed. The results are visualized in six tables, which are illustrated by five figures. In conclusion, the dependence of Anthropometric status is noted in accordance with the height and length of the lower limbs and the width of the pelvis. The dynamic retention of the balance in landing position is more effective than the static balance in the Romberg posture, which is explained by the specificity of the sport figure skating. There is a worsening of the balance in the increase of anthropometric parameters - height, weight and chest circumference. Balance fluctuations in the Romberg position are significantly dependent on the weight and chest circumference, while the height of the skaters affects the balance - with increasing amplitude there is also an increase in balance fluctuations in the landing position after a jump, i.e. the balance is unstable, which is explained by a higher placement of the center of gravity of the body.
\end{abstract}

Key words: figure skating, anthropometric factors, balance stability

\section{INTRODUCTION}

Figure skating is a sport with a complex coordination structure, where movements are performed on the ice by turns, changes of direction and speed combined with additional elements such as Jumps, Jump Combinations and Jump Sequences, Step Sequences, Lifts, Throw Jumps, Death Spirals, Spins and entering into them. All movements of the skaters are performed by sliding with limited support and at a remote center of body weight from the supporting area, therefore, the performance of each element includes a balance component. The precise execution of relatively simple movements cannot be performed perfectly without a sufficiently high level of development of the body structure which keeps the body of the figure skater in balance (Lyussi, Richards, 1959).

Experienced coaches argue that the movement on the ice is to be at one with balance, and then, further in the process of finding a 
balance, the beginner learns the art of ice skating (Gikova, Tishinov, Zareva \& Albert, 2012; Tishinov, Albert, 2010).

In Free Skating Jumps, Spins, Spirals and Step Sequences are connected in conditions of continuous gliding in different poses and require a good sense of balance (Panin, 1956). No matter how technically well the jumps are performed, losing balance in the landing phase or falling after the landing, touching of the ice with hand or with the "free" foot spoil the impression of the figure skater's performance and diminish the judges' marks.

One of the characteristics of modern figure skating is the progressive complication of the competitive programs. This process develops, in particular, in the way athletes master complex coordination elements and compounds of a rotating nature, which appear to be a strong irritant to the vestibular analyzer. The leading place in the programs of the highly qualified skaters today is occupied by Jumps, executed in three and four revolutions by $360^{\circ}$, Spins and Steps with the highest level of complexity. Good balance stability plays a major role in the implementation of all these elements.

The figure skater's ability to orient themselves in space and time, to quickly and accurately perform the most complicated movements under conditions of small and unstable support is achieved by improving the analysts involved in the balance reactions. To them, except the vestibular analyzer, relate also the visual and motor analyzers. A sufficient level of development of the balance allows for a faster mastery of the intricate technique of different physical exercises at a higher technical level (Bondarevskiy, 1976).

Balance is the ability of people to hold the body or certain segments of the body at a certain position as a result of a complex collaboration of many organs and systems aimed at opposing the forces of gravity under conditions of predominantly vertical gravity - defined as a static balance (i.e. balance in static posture). The presence of oscillating movements from the center of gravity of the body is present due to unsustainable, according to the sports biomechanics, peculiarity of the posture of the skater - the support of the athlete is lower in relation to the general center of gravity of the body. In the dynamic balance of the figure skater besides the vertical force of the weight, there is also an acting inertial centrifugal force resulting from the movement of the athlete on a curvilinear trajectory over the ice surface. Thus, when sliding along the arc, the centrifugal force is directed towards the outer side of the trajectory. The power of weight forms a balancing torque directed inward to the radius of the curved trajectory. The two rotating momentums are mutually balanced against the supporting surface of the skating blade. The power of weight counteracts the action of centrifugal force, the torque of which is directed in the opposite direction. Thus, this kind of balance is dynamic (balance in motion). While preserving a certain posture, the body of a person is not absolutely stationary, but fluctuates all the time - as if for a moment a person loses the balance and restores it again. The more perfect the function of balance in a person is, the quicker it recovers, the less the amplitude of fluctuations are. Therefore, those who are good at balance aren't the ones who never lose it, but who quickly regain it. According to the authors (Gikova, Tishinov, Zareva \& Albert, 2012; Tishinov, Albert, 2010) balance stability is characterized by amplitude and frequency of fluctuations of the center of the gravity of the body relative to the support. It is evident that with the descending centrifugal force and the support on the skating blade, the support is not positioned vertically, but at an angle to the 
ice surface, in a similar fashion to the lines of the inclined position of a motorbike rider's body on curves in racing conditions.

In modern specialized scientific literature, data related to the anthropometric profile of competitive figure skaters is difficult to find or inaccessible. There are some surveys concerning the effect of training figure skating on the height and weight of female skaters. This study concluded that female skaters are relatively shorter and lighter than their peers, but the differences were not statistically significant. Significant differences were noted between girls whose sisters do not do sports (Paluchowska, 2015). Another study examining the variation in anthropometric characteristics and somatotype of female figure skaters by level of competition and discipline suggest that figure skating favors lightness, leanness, higher mesomorphy and lower endomorphy at more elite levels (Monsma \& Malina, 2005). The same results were found in the research of the co-authors Mostaert, Deconinck, Pion, Lenoir in 2016.

Anthropometric measurements should be made in order to study the features of the physical development of young figure skaters and to analyze the relationships between the individual characteristics of body structure and sports success. The study of anthropometric factors is related to sports typology. It informs about the state of physical development and ergonomic anthropometric characteristics of the competitors. The anthropometric profile of sports athletes provides information about the specific morphological selection, as well as the impact of this sport on the indicators of an athlete's body development.

The aim of the study is to investigate the influence of anthropometric factors on the balance stability of female figure skaters.

\section{METHODS}

The tasks of the study are:

1. To measure anthropometric factors of the figure skaters.

2. To measure biomechanical dynamic parameters.

3. To put forth the dependence between the balance stability and the anthropometric factors of figure skaters.

The subject of the study is the dialectic relationship between the anthropometric factors and the balance stability of figure skaters.

The object of the study is anthropometric measurements and signs of the balance stability of figure skaters.

\section{Participants}

Thirty-eight competitive female figure skaters (category Singles) at the age of 11 to 13 years from different skating clubs in Bulgaria voluntarily participated in the study. The skaters' competition levels ranged from Basic Novice to Juniors (as determined by their participation in Bulgarian National Championships and ISU competitions), with all skaters able to perform at least double revolution jumps on ice.

\section{Design of the study}

All study tests were done in the Center for Research and Applied Activity in Sport and Anatomy and biomechanics department of the National Sports Academy with the help of highly qualified specialists for conducting functional research of individuals in laboratory conditions.

We used the following research methods:

- Systematization, processing and analysis of data from scientific and methodical literature on the researched issues.

- Sports-pedagogical testing.

- Math statistical methods.

To obtain current and cumulative information about the latent state and dynamics of de- 
velopment of the individual signs and components of the motor abilities of the subjects studied, all participants took part in sports-pedagogical testing.

The measurement of anthropometric factors is associated with sports typology. It informs about the state of physical development and the ergonomic anthropometric characteristics of the athletes. The anthropometric profile of the athletes of a certain sport provides information about the specific morphological selection, as well as the impact of this sport on the measurement of body development of the athlete. Anthropometric measurement took place during the testing procedure twice: in July 2015 and in August 2017. All athletes underwent an anthropometric assessment of 8 parameters: body height, body weight, chest circumference, lower limb length, shoulder width, pelvic width, foot length (Table 1 - Parameters 1-8). Participants were wearing light clothing and no shoes during measurements. Body height was measured with the use of a Martin anthropometer with an accuracy of $0.1 \mathrm{~cm}$ and body weight was measured with calibrated electronic weighing scale with a precision of $0.1 \mathrm{~kg}$. To measure the shoulder and pelvis width and foot length a spreading caliper with an accuracy of $0.5 \mathrm{~cm}$ was used. Chest volume and length of the lower limbs were measured to the nearest $0.1 \mathrm{~cm}$ with the Lufkin W606PM tape measure. The anthropometric procedures for those measurements were followed strictly.

Table 1. Measured parameters

\begin{tabular}{|c|c|c|c|}
\hline № & Measured parameter & Measure units & Measurement accuracy \\
\hline \multicolumn{4}{|c|}{ Anthropometric Factors } \\
\hline 1 & Body height & {$[\mathrm{cm}]$} & 0.1 \\
\hline 2 & Body Weight & {$[\mathrm{kg}]$} & 0,1 \\
\hline 3 & Chest Volume & {$[\mathrm{cm}]$} & 0.1 \\
\hline 4,5 & Length of right and left lower limbs & {$[\mathrm{cm}]$} & 0.1 \\
\hline 6,7 & Shoulder width, pelvis width & {$[\mathrm{cm}]$} & 0.5 \\
\hline 8 & Foot length & {$[\mathrm{cm}]$} & 0.5 \\
\hline \multicolumn{4}{|c|}{ Biomechanical Dynamic Indicators } \\
\hline 9 & Average (Romberg and Landing Test) & [cm] & 0.01 \\
\hline 10 & Frequency (Romberg and Landing Test) & {$[\mathrm{Hz}]$} & 0.01 \\
\hline
\end{tabular}

Balance stability is determined by the ability of the human body to maintain a vertical position at rest, when walking, jogging, or during various physical activities. The study of balance of the human body during a basic posture is carried out by Posturology. The method is called stabilometry. The results of the static stabilometry of the examinees were obtained by means of a balance stability testing device. It is made up of two platforms with four sensitive pressure detectors placed between them and located on the corners of a square. The detectors are connected to an am- plifier-converter, from where the signals are received through an interface in a computer where they are recorded and analyzed. The technical diagram of the static testing device and the algorithm for processing the signals according to the weight of the examined person were published in 1980 (Tishinov, Mikov, Yordanov). The device is accompanied by a copyright certificate by the Republic of Bulgaria.

Biomechanical dynamic indicators - average and frequency. The "average" dimension represents the mean of the maximum 


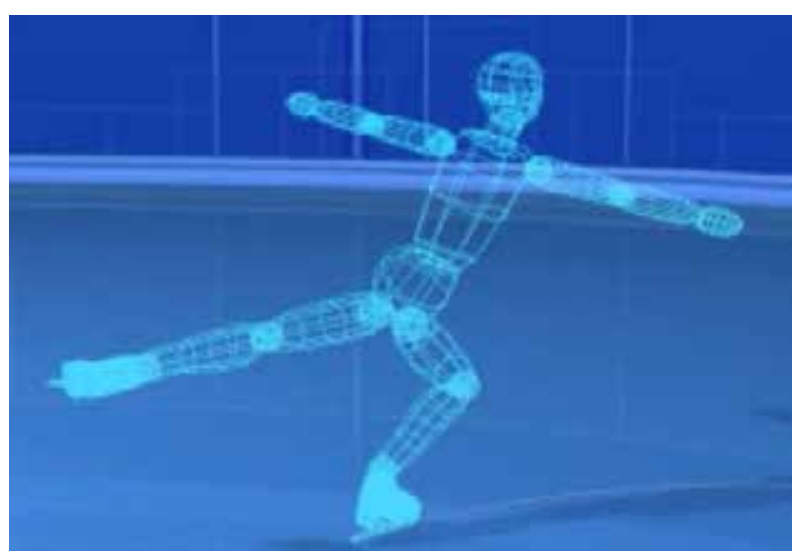

Figure 1. Landing pose

amplitude deviations, and the "frequency" is the number of changes of the equilibrium function for the whole test. Each participant was measured by the method of stabilometry in the Romberg pose and during the landing position after a high jump (Figure 1). During the Romberg test, the athletes raise their foot to their knee, without touching it, and execute the balance on one foot for the designated test time, but no less than 30 seconds in static mode. Upon landing after the jump, they aim as quickly as possible to achieve a minimum of equilibrium fluctuations, which is an active process of the muscles. Their aim is to maintain their balance while performing the test and also to establish the presence of a descending trend in the amplitude of the equilibrium fluctuations. Each athlete made two attempts for each test, of which the better result was used for data.

\section{Data analysis}

The results from the research were processed with math-statistical methods.

Descriptive statistics was used to determine the variability of the studied indicators: calculation of sample's mean $(\bar{X})$, standard deviation $(S)$, coefficient of variation (Var) percentage, which characterizes the homogeneity of the studied population, skewness (As), kurtosis (Ex), maximum, minimum value and
Range - difference between maximum and minimum value.

Correlation analysis was used to evaluate the strength of the relationship between quantitative variables, and what the relationship between anthropometric factors and biomechanical dynamic balance characteristics is.

Comparative analysis T-criterion of Student for the dependent samples was applied to find differences between first and second measurement.

All data were initially recorded in Excel, and the analyses were performed with Statistical Package for the Social Sciences Version 19.

\section{RESULTS AND DISCUSSION}

The movements of figure skating athletes are spatial and are performed on two- and one-foot skating, as well as in the non-supporting position (in the execution of the jump elements) and depend on both the dynamic parameters of the movement and the anthropometric factors of the athlete (Vinogradova, 2013). The studies carried out by V. Vinogradova - 2013 indicate that skaters with a conical shape of the body keep the skating balance better. To create the initial rotation on the jumps, a cylindrical shape of the body is preferable. For the skaters with a cylindrical shape of the body, the angular velocity $\omega$ of the balance sliding is higher. The transformation of this velocity into the rotational speed during the phase of flight around its longitudinal axis increases the jump's rotations.

All anthropometric data from the first and second measurement are shown in Figure 2, where we can clearly see an increase in all factors, which is normal for adolescent girls. The highest growth is in height and the length of the lower limbs, and the lowest - in the width of the pelvis. 


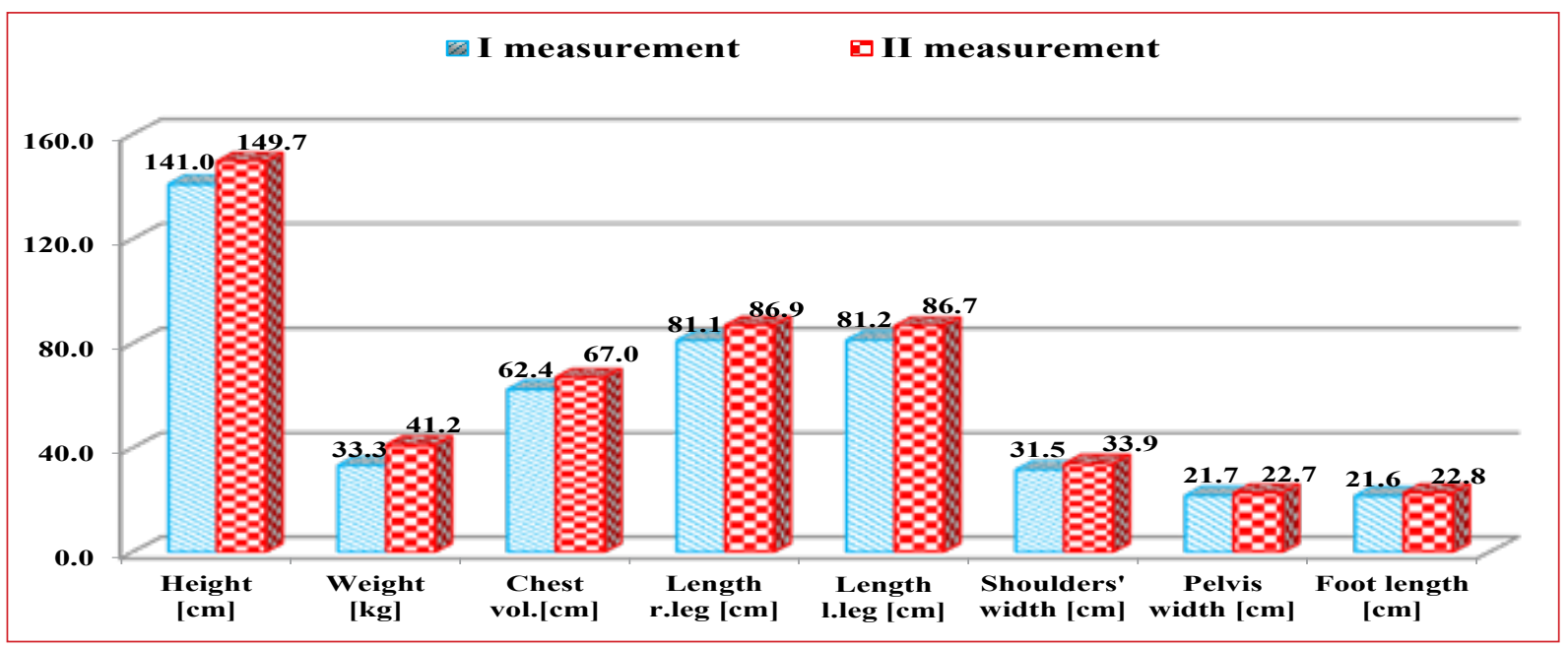

Figure 2. Dynamics of anthropometric variables

The descriptive statistics for the values of the second measurements are shown on Table the anthropometric parameters in the first and 2 and 3.

Table 2. Descriptive statistics of the anthropometric variables - first measurement

\begin{tabular}{ccccccccc}
\hline $\begin{array}{c}\text { Vari- } \\
\text { ables }\end{array}$ & $\begin{array}{c}\text { Body } \\
\text { height } \\
{[\mathbf{c m}]}\end{array}$ & $\begin{array}{c}\text { Body } \\
\text { weight } \\
{[\mathbf{k g}]}\end{array}$ & $\begin{array}{c}\text { Chest } \\
\text { vol. } \\
{[\mathbf{c m}]}\end{array}$ & $\begin{array}{c}\text { Length } \\
\text { of right } \mathbf{l} \text {. } \\
{[\mathbf{c m}]}\end{array}$ & $\begin{array}{c}\text { Length } \\
\text { of left } \mathbf{l .} \\
{[\mathbf{c m}]}\end{array}$ & $\begin{array}{c}\text { Shoulder } \\
\text { width }[\mathbf{c m}]\end{array}$ & $\begin{array}{c}\text { Pelvis } \\
\text { width } \\
{[\mathbf{c m}]}\end{array}$ & $\begin{array}{c}\text { Foot } \\
\text { length } \\
{[\mathbf{c m}]}\end{array}$ \\
\hline $\bar{X}$ & 141.0 & 33.3 & 62.4 & 81.1 & 81.2 & 31.5 & 21.7 & 21.6 \\
$S$ & 10.0 & 8.0 & 5.0 & 6.7 & 6.7 & 2.8 & 2.2 & 1.6 \\
Var & $7 \%$ & $24 \%$ & $8 \%$ & $8 \%$ & $8 \%$ & $9 \%$ & $10 \%$ & $8 \%$ \\
As & -0.1 & 0.7 & 0.4 & 0.2 & 0.2 & -0.1 & 0.3 & 0.3 \\
Ex & -0.7 & 0.3 & -0.3 & -0.1 & -0.1 & -0.6 & 0.1 & -0.2 \\
Max & 158.4 & 54.6 & 73.5 & 95.6 & 95.8 & 36.5 & 26.5 & 25.5 \\
Min & 121.2 & 20.4 & 53.0 & 67.5 & 68.2 & 26.0 & 17.0 & 18.5 \\
Range & 37.2 & 34.2 & 20.5 & 28.1 & 27.6 & 10.5 & 9.5 & 7.0 \\
\hline
\end{tabular}

Table 3. Descriptive statistics of the anthropometric variables - second measurement

\begin{tabular}{|c|c|c|c|c|c|c|c|c|}
\hline $\begin{array}{l}\text { Vari- } \\
\text { ables }\end{array}$ & $\begin{array}{c}\text { Body } \\
\text { height } \\
{[\mathrm{cm}]}\end{array}$ & $\begin{array}{c}\text { Body } \\
\text { weight } \\
{[\mathrm{kg}]} \\
\end{array}$ & $\begin{array}{c}\text { Chest } \\
\text { vol. } \\
{[\mathrm{cm}]} \\
\end{array}$ & $\begin{array}{c}\text { Length } \\
\text { of right } 1 . \\
\text { [cm] }\end{array}$ & $\begin{array}{l}\text { Length of } \\
\text { left } 1 .[\mathrm{cm}]\end{array}$ & $\begin{array}{c}\text { Shoulder } \\
\text { width } \\
{[\mathrm{cm}]}\end{array}$ & $\begin{array}{c}\text { Pelvis } \\
\text { width } \\
{[\mathrm{cm}]}\end{array}$ & $\begin{array}{c}\text { Foot } \\
\text { length } \\
{[\mathrm{cm}]}\end{array}$ \\
\hline $\bar{X}$ & 149.7 & 41.2 & 67.0 & 86.9 & 86.7 & 33.9 & 22.7 & 22.8 \\
\hline$S$ & 9.4 & 9.4 & 5.3 & 5.6 & 5.3 & 2.8 & 2.2 & 1.3 \\
\hline Var & $6 \%$ & $23 \%$ & $8 \%$ & $6 \%$ & $6 \%$ & $8 \%$ & $10 \%$ & $6 \%$ \\
\hline As & -0.5 & 0.4 & 0.2 & -0.2 & -0.1 & -0.2 & -0.1 & -0.2 \\
\hline$E x$ & -0.6 & -0.2 & 0.2 & -0.6 & -0.4 & -0.6 & 0.3 & -0.6 \\
\hline Max & 163.4 & 64.0 & 81.0 & 97.2 & 97.2 & 39.0 & 28.0 & 25.5 \\
\hline Min & 130.0 & 25.4 & 58.0 & 76.0 & 76.5 & 28.0 & 18.0 & 20.0 \\
\hline Range & 33.4 & 38.6 & 23.0 & 21.2 & 20.7 & 11.0 & 10.0 & 5.5 \\
\hline
\end{tabular}

The low values of coefficients of variation tribution of the quoted data of the sample in (up to $24 \%$ ), skewness and kurtosis (Table 2 question. The established normal distribution and 3) give us reason to assume a normal dis- gives us reason to make a comparative analysis 
of the test sample with the T-criterion of Student for the dependent samples, due to the fact that the same contingents of investigated individuals were compared. The empirical value of the t-Student's test exceeds the tabulated and identified critical levels (Table 4). An additional circumstance is the fact that the guaranteed probability $\mathrm{P}_{t}[\%]$ exceeds the critical $(95 \%)$ value. Thus, with confidence we may reject the null hypothesis and accept the alternative for the presence of a significant increase in data from the test sample, relating to the growth in the anthropometric parameters (Figure 2).
Some influence on them is also due to the acceleration factor of adolescent athletes, which has been observed in recent decades. Acceleration is observed in the physical data but also in the anthropometry of the body: today children who are engaged in figure skating are tall, slender and with long legs. In Table 4 and Figure 3 we present the data from the initial and final studies, as well as the absolute value of the growth and its percentage equivalent. For clarity, the line shows the calculated ratio of Student's t-distribution and the guaranteed probability $\mathrm{P}_{\mathrm{t}}$.

Table 4. Comparative analysis of the variables

\begin{tabular}{lcccccc}
\hline \multicolumn{1}{c}{ Variables } & I meas. & II meas. & d & D [\%] & t & $\mathbf{P}_{\mathbf{t}}[\mathbf{\%} \mathbf{0}]$ \\
\hline Body height [cm] & 141.0 & 149.7 & 8.8 & 6.2 & -16.5 & 100.00 \\
Body weight [kg] & 33.3 & 41.2 & 7.9 & 23.7 & -13.6 & 100.00 \\
Chest vol. [cm] & 62.4 & 67.0 & 4.6 & 7.4 & -12.1 & 100.00 \\
Length right leg [cm] & 81.1 & 86.9 & 5.8 & 7.1 & -11.8 & 100.00 \\
Length left leg [cm] & 81.2 & 86.7 & 5.5 & 6.7 & -11.4 & 100.00 \\
Shoulder width [cm] & 31.5 & 33.9 & 2.4 & 7.6 & -11.0 & 100.00 \\
Pelvis width [cm] & 21.7 & 22.7 & 1.0 & 4.5 & -4.2 & 99.98 \\
Foot length [cm] & 21.6 & 22.8 & 1.1 & 5.3 & -10.0 & 100.00 \\
\hline
\end{tabular}

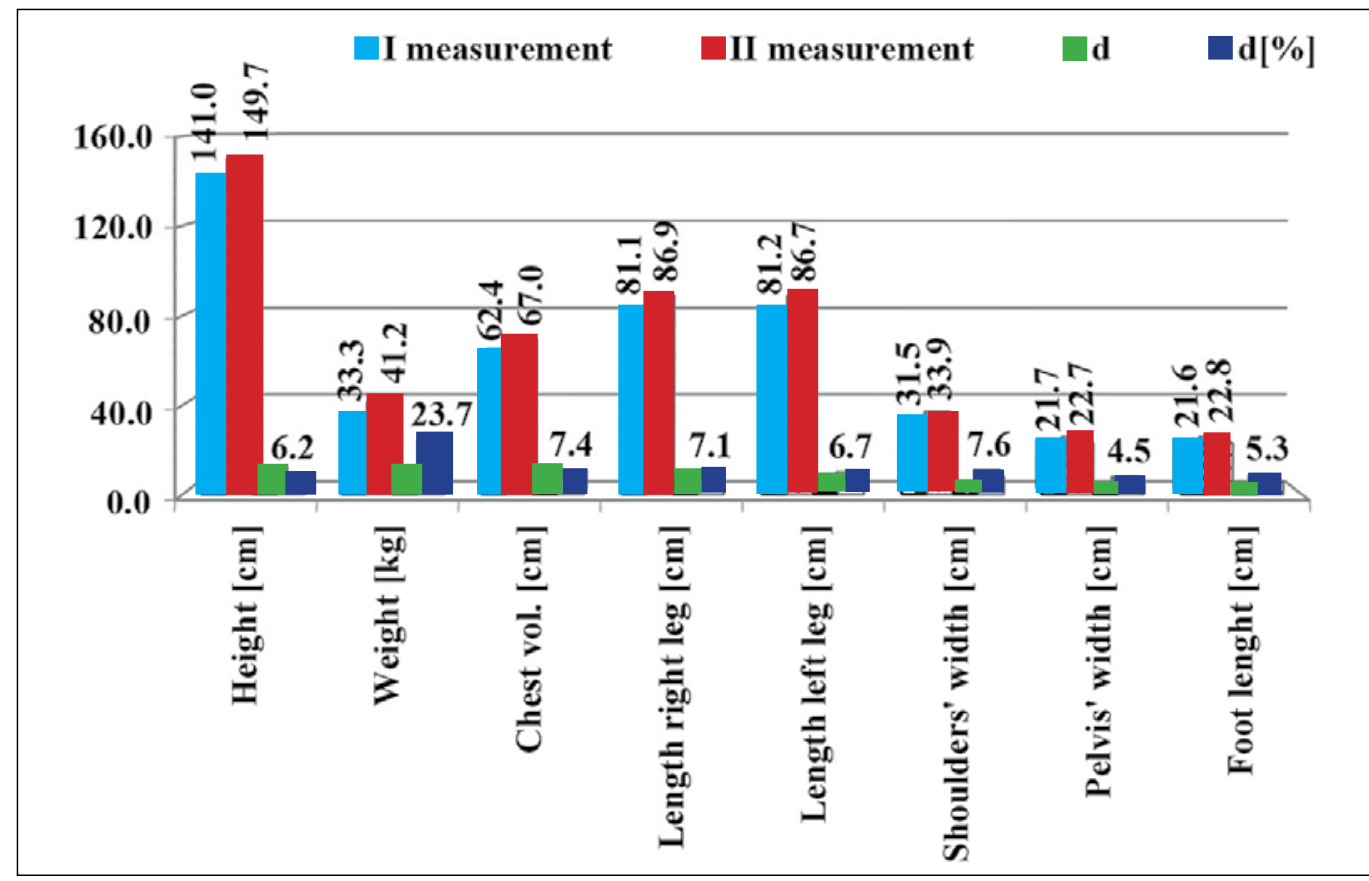

Figure 3. Growth anthropometric variables

The study of the balance stability of skaters during the landing position after a high jump. is realized by testing in the Romberg pose and During the Romberg test, the participants raise 
their foot to their knee, without touching it, and execute the balance on one foot for the designated test time, but not less than 30 seconds in static mode. Upon landing after the jump, the participants aim as quickly as possible to achieve a minimum of balance fluctuations, which is an active process for the muscles in their aim to manage the balance when performing the test and also to establish the presence of a descending trend in the amplitude of the balance fluctuations. This quality of the balance apparatus is valuable in terms of improving the technical mastery and skills of figure skaters.

The basis of figure skating is sliding, mainly in a single support position. The art of sliding is achieved as a result of management of a number of components, such as a correct pose, sense of balance etc. (Mishin, 1981). G. Lyussi and M. Richards (1959) considered that "the first condition for practicing figure skating, without which progress is absolutely impossible, is to find a proper and natural balance. Only with a sense of balance can the movements of figure skating be successfully absorbed."
A large load on the vestibular system is caused by performing multi-revolution jumps, spins, etc. The execution of repeated rotations during jumps, followed by a soft landing on one-foot sliding, requires the precision of movement in time and space.

Scientists' research shows that skaters are able to withstand significant rotational loads, while retaining the accuracy of performed movements.

The balance oscillations after landing in jumps are characterized by a downward trend. Even in the researches of L. V. Latmanizova's (1931) it was found that there is a connection between balance, dynamic indicators and speed-force capabilities.

The manifestation of the speed-force capabilities in performing a wide range of tasks is determined by the level of muscle development, which simultaneously perform a function against gravity. It is known that the correct mutual disposition of the units of the body has a significant influence on muscle tension and fluctuations of the center of gravity.

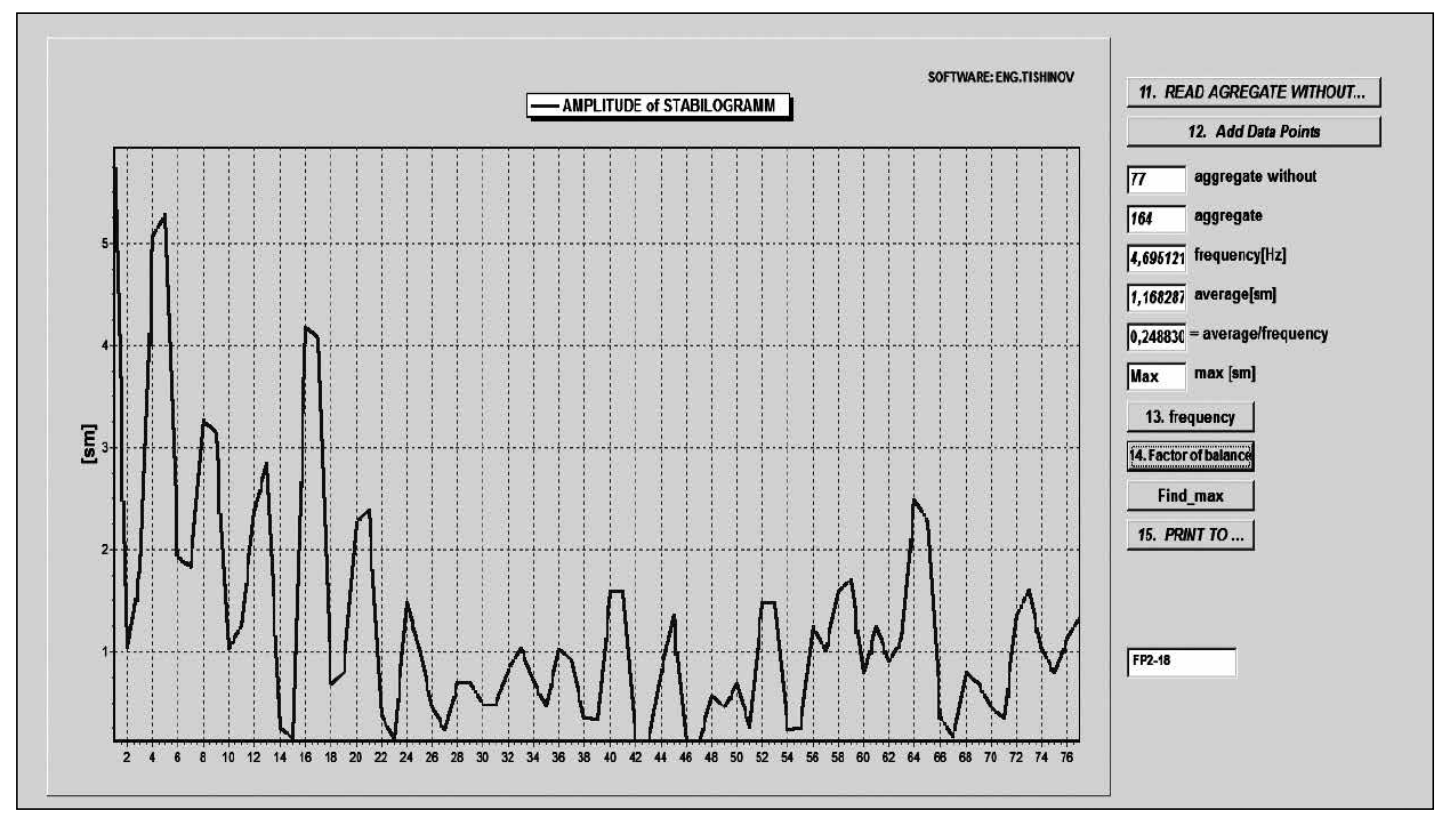

Figure 4. Standing in balance position - landing after a jump-maximum amplitude deviations

In Figure 4 the vector sum is in a declining "average" dimension represents the mean of trend, which is a proof of a good balance. The the maximum amplitude deviations, and the 
"frequency" is the number of changes of the balance function for the entire duration of the study. It is evident that the quality of minimizing balance fluctuations is very useful in sports practice.

The studied amplitude average variables and the instability factor found in the Romberg test and upon landing after a jump are statistically significant $\left(\mathrm{P}_{\mathrm{t}}\right.$ was higher than 95\%). This is completely logical, since both exercises are quite different in nature. On the other hand, the frequency of the balance function does not change in statistically significant way, since the guarantee probability is $80 \%$ and is lower than the limit value $(95 \%)$ (Table 5).

Table 5. Comparative analysis of the variables between two tests - Landing and Romberg

\begin{tabular}{ccccccc}
\hline \multirow{2}{*}{ Variables } & \multicolumn{3}{c}{ "Landing" test } & \multicolumn{3}{c}{ "Romberg" test } \\
\cline { 2 - 5 } & $\begin{array}{c}\text { average } \\
{[\mathbf{c m}]}\end{array}$ & $\begin{array}{c}\text { frequency } \\
{[\mathbf{H z}]}\end{array}$ & factor & average [cm] frequency [Hz] & factor \\
\hline $\bar{X}$ & 3.60 & 4.63 & 0.72 & 7.62 & 4.94 & 1.76 \\
$S$ & 1.82 & 0.94 & 0.43 & 3.56 & 0.51 & 0.94 \\
$V a r$ & $51 \%$ & $20 \%$ & $59 \%$ & $47 \%$ & $10 \%$ & $54 \%$ \\
$E x$ & 1.68 & 10.56 & 2.28 & 1.35 & -0.21 & -0.17 \\
$A s$ & 1.02 & -2.92 & 1.25 & 1.05 & 0.30 & 0.72 \\
$M a x$ & 8.65 & 5.50 & 1.95 & 17.05 & 6.01 & 3.77 \\
$M i n$ & 1.17 & 1.11 & 0.21 & 3.21 & 4.00 & 0.53 \\
$R$ & 7.48 & 4.39 & 1.74 & 13.84 & 2.01 & 3.24 \\
\hline$t$ Romberg/Landing & -4.96 & -1.35 & -4.65 & Statistically significant differences \\
\cline { 1 - 4 }$P_{+}[\%]$ Romberg/Landing & 100.0 & 80.5 & 100.0 & were found between two tests \\
\hline
\end{tabular}

An interesting fact is that during the Romberg test we received higher average values (average $=7,62 \mathrm{~cm}$ ), as opposed to the test landing after a jump, which obtained the average $=3,60 \mathrm{~cm}$ (Figure 5). The dynamic retention of balance after the jump is more efficient than the static balance position Romberg, which is explained by the specificity of the sport figure skating.

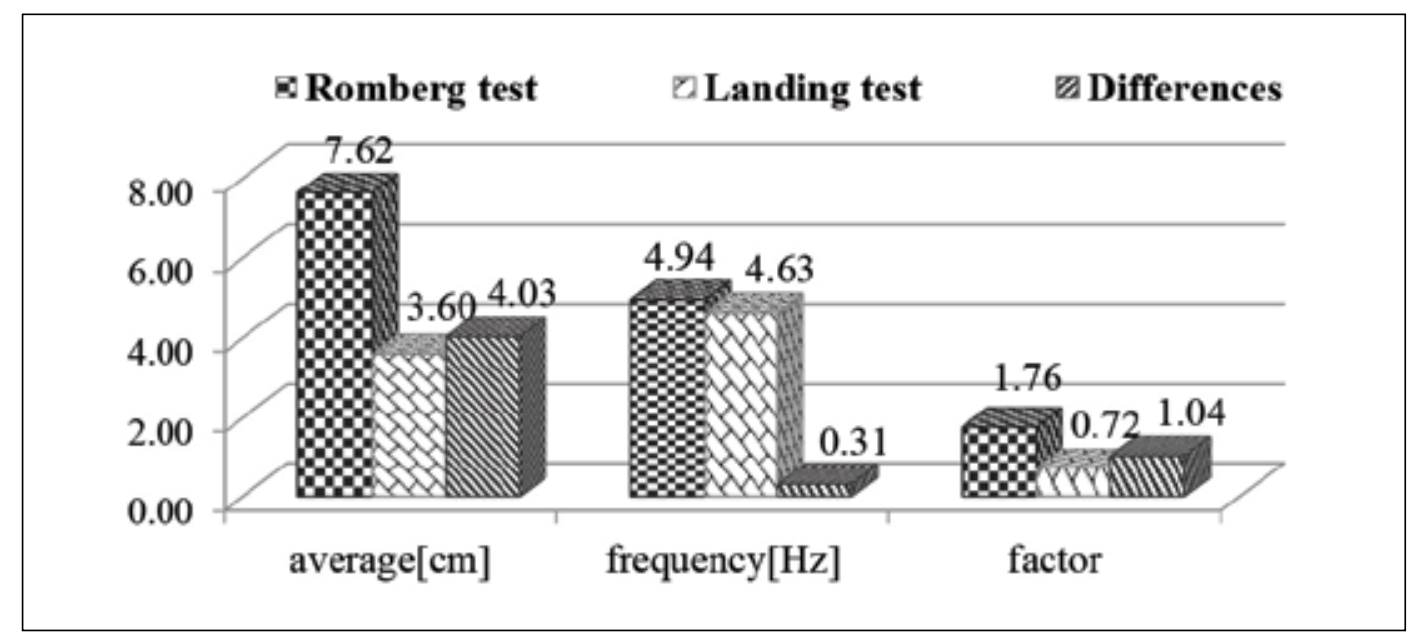

Figure 5. Differences in absolute values in "Romberg" test and landing after the jump

The correlation analysis of the variables in vided into two groups. One of these groups is the study sample of the group of competitors the results of the anthropometric tests, and the (Table 6) includes an analysis with Pearson's second one is balance variables. multiple correlation. The variables can be di- 
Table 6. Correlations of anthropometric and balance variables

\begin{tabular}{|c|c|c|c|c|c|c|c|c|c|c|c|c|}
\hline Height & & & & & & & & & & & & \\
\hline Weight & $.876 * *$ & & & & & & & & & & & \\
\hline Chest. Vol.[cm] & $.830 * *$ & $.955^{* *}$ & & & & & & & & & & \\
\hline Length r. leg [cm] & $.966 * *$ & $.811 * *$ & $.734 * *$ & & & & & & & & & \\
\hline Length $1 . \operatorname{leg}[\mathrm{cm}]$ & $.971 * *$ & $.839 * *$ & $.768 * *$ & $.989 * *$ & & & & & & & & \\
\hline Shoulders' width [cm] & $.918 * *$ & $.869 * *$ & $.866 * *$ & $.849 * *$ & $.843 * *$ & & & & & & & \\
\hline Pelvis' width [cm] & $.682 * *$ & $.732 * *$ & $.674 * *$ & $.691 * *$ & $.696 * *$ & .653 ** & & & & & & \\
\hline Foot length $[\mathrm{cm}]$ & $.899 * *$ & $.798 * *$ & $.762^{* * *}$ & $.886^{* * *}$ & $.853^{* *}$ & $.803^{* *}$ & $.527^{*}$ & & & & & \\
\hline Average [cm] Romberg & .377 & $.499^{*}$ & $.508^{*}$ & .398 & .431 & .470 & .261 & .297 & & & & \\
\hline $\begin{array}{l}\text { Frequency }[\mathrm{Hz}] \\
\text { Romberg }\end{array}$ & .386 & .237 & .377 & .261 & .265 & .400 & .375 & .251 & -.137 & & & \\
\hline Factor Romberg & .288 & .458 & .436 & .319 & .355 & .371 & .189 & .241 & $.973^{* *}$ & -.341 & & \\
\hline Average $[\mathrm{cm}]$ landing & $.496^{*}$ & .449 & .393 & .446 & .443 & $.484 *$ & .242 & .460 & .415 & .144 & .372 & \\
\hline Frequency $[\mathrm{Hz}]$ landing & -.410 & -.142 & -.069 & -.435 & -.389 & -.268 & -.083 & -.443 & -.089 & -.001 & -.102 & $2-.414$ \\
\hline Factor landing & .388 & .138 & .057 & .436 & .378 & .266 & .074 & .460 & .142 & -.024 & .141 & $.597^{*}-.924 *$ \\
\hline
\end{tabular}

Marked variables in bold and with * or ** indicate the presence of significant dependencies.

Intragroup correlations for anthropometric factors are significant in nature and include height/weight (.876), height/chest (.830), height/length of the right foot (.966), height/ length of the left foot (.971), height/width of the shoulders (.918), height/width of the pelvis (.682), height/length of the foot (.899). In an analogous manner are presented significant correlations between weight relative to the chest circumference (.955), right leg (.811), left leg (.839) and length of the foot (.798). Those present correlations are positive in nature and express the proportional relationship between the variables presented in the study. This circumstance means that the growth of one of them will increase the others. The following dependencies are presented between the anthropometric and balance variables: the Romberg test against body weight (.499) and the chest circumference (.508). Increasing the amplitude score (average) means that the balance is aggravated by the increase in the quoted weight and chest circumference, which is completely logically possible. In the group, including balance fluctuations, there are significant correlation coefficients - factor Romberg/average (.973), factor landing/frequency
(-.924). These dependencies are determined by the formula for calculating the ratio for balance factor = average/frequency, where average is the mean value of the maximum deviations in the balance function, and frequency is the frequency (the total number of these deviations as maximum and minimum values per second). Thus, these extremes determine how effectively the balance apparatus interacts with the supporting area. The nature of the rebound from the support must also be considered - with the pre-insertion of the kinematic chain in the position of half-squat.

Marked shaded rectangles, supplemented by one or two asterisks, indicate the presence of significant dependencies. For those variables, we can assume with confidence that the null hypothesis is rejected and there is an alternative to the significance of the variables of the study sample.

\section{CONCLUSION}

Descriptive statistics of the variables of anthropometric status of the surveyed figure skaters has a normal distribution in both measurements, and marks an increase, the highest growth rate is measured in height and length 
of the lower limbs, and the lowest in the width of the pelvis. The comparative analysis with T-criterion of Student for the dependent samples proved statistically significant increase in anthropometric factors of tested athletes in figure skating. The dynamic retention of the balance in landing position is more effective than static balance in the Romberg posture, which is explained by the specificity of figure skating. However, there is a worsening of the balance in increasing of anthropometric parameters - height, weight and chest circumference. Balance fluctuations in the Romberg position are significantly dependent on the weight and chest circumference $-r-.499$ .508 , while the height of the skaters affects the balance - with increasing amplitude there is also an increase in balance fluctuations in the landing position after a jump, i.e. the balance is unstable, which is explained by a higher placement of the center of gravity of the body.

\section{REFERENCES}

Bondarevskiy, E. Ya. (1976). Otsenka fizicheskoy podgotovlennosti, Fizkultura i sport, Moskva. // Бондаревский, Е. Я. (1976), Оценка физической подготовленности. Физкультура и спорт, Москва.

Vinogradova, V. I. (2013). Osnovi biomehaniki prizhkov v figurnom katanii, Sovetskiy sport, Moskva. // Виноградова, В. И. (2013). Основы биомеханики прыжков в фигурном катании, Советский спорт, Москва.

Gikova, M., Tishinov, O., Zareva, I. \& Albert, E. (2012). "Comparative analysis of the balance stability in ballet, rhythmic gymnastics and chi gunk athletes", Sport and Science (56) LVI (5), pp. 33-39.

Gigova, V. (2014). Statisticheski metodi sus SPSS Statistics 19, Sofia. // Гигова, В. (2014). Статистически методи със SPSS Statistics 19, София.
Glyazer, S. V. (1969). Azbuka nachinayushtego figurista, Fizkultura i sport, Moskva. // Глязер, С. В. (1969). Азбука начинающего фигуриста, Физкультура и спорт, Москва.

Latmanizova, L. V. (1931). Ergebnisse aus zephalographischen Aufzeichnungen. Arbeiten des Leningrader Inst. Zum stadium von Berufskrankheiten, Bd. 5.

Lyussi, G., Richards, M. (1959). Figurnoe katanie na konkah, Fizkultura i sport, Moskva. // Люсси, Г., Ричардс, М. (1959). Фигурное катание на коньках, Физкультура и спорт, Москва.

Mishin, A. N. (1981). Biomehanika dvizheniy figuristov, Fizkultura i sport, Moskva. // Мишин, А. Н. (1981). Биомеханика движений фигуристов, Физкультура и спорт, Москва.

Monsma, D. \& Malina, R. (2005). Anthropometry and somatotype of competitive female figure skaters 11-22 years. Variation by competitive level and discipline. J Sports Med Phys Fitness. 2005 Dec; 45(4):491-500.

Mostaert, M., Deconinck, F, Pion, J., Lenoir, M. (2016). Anthropometry, Physical Fitness and Coordination of Young Figure Skaters of Different Levels. International Journal of Sports Medicine. 2016 Jun; 37(7):531-8. doi: 10.1055/s-0042-100280.

Paluchowska, M. (2015). The Role of Intense Physical Activity in the Formation of Body Shape - Research Based on Female Figure Skaters. Pomeranian journal of life sciences, 61 (3), pp.310-4.

Panin, N. A. (1956). Iskusstvo figurista, Fizkultura i sport, Moskva. // Панин, Н. A. (1956). Искусство фигуриста, Физкультура и спорт, Москва.

Tishinov, O., Albert, E. (2010). Izsledvane na ravnovesnata ustoychivost pri statichno-silovi uprazhnenia $\mathrm{v}$ iztochnite boyni iskustva, 5-ti mezhdunaroden kongres "Sport, stress, adaptatsia”. // Тишинов, О., Алберт, 
Е. (2010). Изследване на равновесната устойчивост при статично-силови упражнения в източните бойни изкуства, 5-mu международен конгрес „Спорт, стрес, адаптациия ".

Tishinov, O., Mikov, Ts., Yordanov, N. Техника вращательных упражнений фигу(1980). “Stabilograf” AS No.33600 na IIR. риста и методика обучения. Диссертация // Тишинов, О., Миков, Ц., Йорданов, Н. на соискание степени кандидата педагоги(1980). Стабилограф, АС №33600 на ИИР. ческих наук, Ленинград, ГДОИФК.

\section{Corresponding author:}

Tatiana Yordanova

Technical and Ice Sports department National Sports Academy "Vassil Levski" 21, Acad. Stefan Mladenov str. Sofia 1700, Bulgaria E-mail: tania.yordanova@online.bg 